\title{
Development and GBS-genotyping of introgression lines (ILs) using two wild species of rice, $O$. meridionalis and $O$. rufipogon, in a common recurrent parent, $O$. sativa cv. Curinga
}

\author{
Juan D. Arbelaez $\cdot$ Laura T. Moreno $\cdot$ Namrata Singh $\cdot$ Chih-Wei Tung • \\ Lyza G. Maron • Yolima Ospina • César P. Martinez • Cécile Grenier • \\ Mathias Lorieux $\cdot$ Susan McCouch
}

Received: 22 August 2014 / Accepted: 29 January 2015/Published online: 14 February 2015

(C) The Author(s) 2015. This article is published with open access at Springerlink.com

\begin{abstract}
Two populations of interspecific introgression lines (ILs) in a common recurrent parent were developed for use in pre-breeding and QTL mapping. The ILs were derived from crosses between cv Curinga, a tropical japonica upland cultivar, and two different wild donors, Oryza meridionalis $\mathrm{Ng}$. accession (W2112) and Oryza rufipogon Griff. accession (IRGC 105491). The lines were genotyped using genotyping-by-sequencing (GBS) and SSRs. The 32 Curinga/O. meridionalis ILs contain $76.73 \%$ of the donor genome in individual introgressed segments,
\end{abstract}

Electronic supplementary material The online version of this article (doi:10.1007/s11032-015-0276-7) contains supplementary material, which is available to authorized users.

J. D. Arbelaez · N. Singh · L. G. Maron .

S. McCouch $(\square)$

Department of Plant Breeding and Genetics, Cornell

University, 162 Emerson Hall, Ithaca, NY 14853-1901,

USA

e-mail: srm4@cornell.edu

\section{T. Moreno}

School of Botany, The University of Melbourne,

Parkville, VIC 3010, Australia

\section{C.-W. Tung}

Department of Agronomy, National Taiwan University,

No. 1, Section 4, Roosevelt Road, Taipei 106, Taiwan

\section{Y. Ospina - C. P. Martinez}

Rice Program, International Center for Tropical

Agriculture (CIAT), AA6713 Cali, Colombia and each line has an average of $94.9 \%$ recurrent parent genome. The 48 Curinga/O. rufipogon ILs collectively contain $97.6 \%$ of the donor genome with an average of $89.9 \%$ recurrent parent genome per line. To confirm that these populations were segregating for traits of interest, they were phenotyped for pericarp color in the greenhouse and for four agronomic traits-days to flowering, plant height, number of tillers, and number of panicles-in an upland field environment. Seeds from these IL libraries and the accompanying GBS datasets are publicly available and represent valuable genetic resources for exploring the genetics and breeding potential of rice wild relatives.

\author{
C. Grenier \\ CIRAD-AGAP 34394, Montpellier Cedex 5, France \\ M. Lorieux \\ DIADE Research Unit, Institut de Recherche Pour le \\ Développement, 34394 Montpellier Cedex 5, France \\ M. Lorieux \\ Rice Genetics and Genomics Laboratory, International \\ Center for Tropical Agriculture (CIAT), AA6713 Cali, \\ Colombia
}


Keywords Rice - Oryza sativa - Crop wild relatives Chromosome segment substitution lines (CSSLs) . Allele discovery · Marker-assisted selection (MAS) · Genotyping by sequencing (GBS)

\section{Introduction}

Asian rice (Oryza sativa L.) is the staple crop for 3 billion people around the world (Food and Agricultural Organization 2003; Bouman et al. 2007). To meet the growing demand for food driven by population growth and economic development, global rice production must double by 2050 (Ray et al. 2013). Much of this increase is expected to come from new crop varieties that are high yielding, resource-use efficient and resistant to diseases, insects and abiotic stresses, problems that are exacerbated by climate volatility (Godfray et al. 2010; Tester and Langridge 2010). Genetic variation is the raw material used by plant breeders to improve traits and characteristics of interest for producers and consumers (Asíns 2002). While intensive breeding for modern, high-yielding varieties has globally reduced the genetic diversity of crops in farmers' fields, there is still abundant natural variation in landraces and crop wild relatives conserved in national and international gene banks that can be tapped to accelerate crop improvement for the future (Asano et al. 2011; Gao et al. 2006; Lorieux et al. 2004; McCouch et al. 2013).

Wild relatives of rice are of particular interest as donors of genetic variation because they contain a variety of traits and trait complexes that were eliminated from the cultivated gene pools during the early phases of crop domestication. Wild genetic diversity is most effectively tapped for crop improvement through the creation of interspecific populations via backcrossing with a well-adapted and productive cultivar-a practice that is often termed 'pre-breeding'. Yet this process is labor and time-consuming and typically fraught with difficulties due to incompatibility barriers, limited recombination, and linkage drag, all of which limit the ease of identifying, transferring, and utilizing beneficial wild alleles in crop improvement (Lorieux et al. 2004; Brar and Khush 1997; Tanksley and McCouch 1997).

The use of DNA-marker technology has greatly accelerated the development of pre-breeding populations and facilitated the targeted introduction of useful variation into elite breeding backgrounds. It has also enabled dissection of quantitative trait locus (QTL) and the discovery of wild alleles underlying traits of agronomic importance (Wang et al. 1992; Song et al. 1995; Zamir 2001; Collard and Mackill 2008; Chin et al. 2011; Periyannan et al. 2013; Saintenac et al. 2013). Recent developments in next generation sequencing, including the use of reduced representation libraries in genotyping by sequencing (GBS), have further reduced the cost and increased the resolution and throughput of trait mapping and marker-assisted breeding, making it faster and easier to genetically characterize and select lines with favorable wild alleles for use in breeding.

Advanced backcross populations, such as nearisogenic lines (NILs) (Inukai et al. 1996; Takahashi et al. 2001; Maas et al. 2010; Imai et al. 2013), Introgression Lines (ILs) (Thomson et al. 2003, 2006; Tian et al. 2006; Gutierrez et al. 2010; Ogawa et al. 2014), and chromosome segment substitution lines (CSSLs) (Kubo et al. 2002; Ebitani et al. 2005; Ando et al. 2008; Ali et al. 2010; Xu et al. 2010) are commonly used when working with intra and interspecific crosses of rice. In these materials, small chromosomal segments containing alleles from a wild donor parent are systematically introduced into a cultivated genetic background using marker-assisted selection (MAS). Each line contains only one or few well-defined introgressions in an adapted, recurrent parent (RP) background. This is advantageous so the effect of individual wild alleles can be determined in the genetic background of a commercially acceptable variety (Tanksley and Nelson 1996; Kubo et al. 2002; Ebitani et al. 2005; Kanbe et al. 2008; Ali et al. 2010; Gutierrez et al. 2010). In addition, when fixed lines are used for evaluation, identical genotypes can be evaluated repeatedly in different seasons and environments to improve the accuracy of QTL detection (Liu et al. 2008). ILs can also be used to rapidly develop secondary $F_{2}$ populations for fine mapping and positional cloning of interesting genes and QTL (Yano et al. 2000).

The two wild species used as donors in this study, $O$. meridionalis $\mathrm{Ng}$. and $O$. rufipogon Griff., both carry the AA genome and are cross-compatible, but are estimated to have diverged approximately 2 million years ago (Park et al. 2003; Ren et al. 2003; $\mathrm{Zhu}$ and $\mathrm{Ge} 2005)$. O. meridionalis is considered to be the basal lineage of the AA genome species and is the 
most divergent with respect to cultivated Asian rice, $O$. sativa (Zhu et al. 2014). In contrast, O. rufipogon is considered to be the immediate ancestor of $O$. sativa. $O$. meridionalis is native to Australia and some regions of West Papua and Indonesia (Ng et al. 1981; Lu and Silitonga 1999), while O. rufipogon is found throughout tropical mainland and South East Asia.

In this study, we apply marker-assisted backcrossing (MABC) to develop two sets of advanced backcross ILs by crossing an $O$. meridionalis accession, W2112, hereafter referred to as $M E R$, and an $O$. rufipogon accession, IRGC 105491, hereafter referred to as $R U F$, with a tropical japonica cultivar from Brazil, cv Curinga, hereafter referred to as CUR (de Morais et al. 2005). Few attempts to develop prebreeding materials utilizing $M E R$ as a donor have been reported (Yoshimura et al. 2010; Doi et al. 2003), while $R U F$ has been used in several previous QTL and pre-breeding studies and is known to carry favorable alleles for yield and yield components (Xiao et al. 1998; Moncada et al. 2001; Thomson et al. 2003; Septiningsih et al. 2003; Marri et al. 2005; McCouch et al. 2007; Imai et al. 2013).

We demonstrated the usefulness and versatility of these ILs for genetic mapping and as pre-breeding germplasm by evaluating their segregation for one Mendelian trait, red pericarp, and four quantitative traits, flowering time, plant height, tiller number and panicle number, based on greenhouse and field studies. Red pericarp is a highly heritable trait, regulated by the $R C$ gene (Sweeney et al. 2006). A 14-bp deletion in the sixth exon of $R C$ is the most common mutation leading to white pericarp. The functional version of $R C$ is found in virtually all wild rice and confers both red grain color and seed dormancy. While both traits were selected against during rice domestication, some degree of dormancy is still important in white pericarp cultivars where pre-harvest sprouting may otherwise become a problem ( $\mathrm{Gu}$ et al. 2011). More recently, cultivated red rice varieties, such as the Buthanece Red, Thai Red Cargo and the French Camargue Red Rice, have sought to bring back the health benefits associated with pigmented pericarp, while avoiding the problems associated with excessive degrees of dormancy. These varieties have the potential to be commercialized in the rice specialty varieties market.

We also evaluated the collection of $C U R / R U F$ introgression lines for four agronomic traits, flowering time, plant height, tiller number, and panicle number, under upland field conditions. Rice grown in the upland farming system constitutes only $12 \%$ of the total area planted on a global basis, but in Latin America, it accounts for $45 \%$ of rice area, with $69.6 \%$ of rice in Brazil and $23 \%$ in Colombia grown as a dry land crop (Moncada et al. 2001). Many upland soils are highly acidic, making it necessary to breed for acid soil tolerance as well as yield potential for these systems. We were interested to determine whether particular $O$. rufipogon-derived alleles might confer positive effects in the CUR genetic background for the four traits of interest, and to determine the effect of the introgressions in soils that were naturally acidic $(\mathrm{pH}<5.0)$ and in soils that were limed $(\mathrm{pH}>5.0)$.

\section{Materials and methods}

\section{Plant materials}

The common recurrent parent Curinga (O. sativa ssp. tropical japonica) (CUR) is a commercial rice variety released in 2005, developed by the Empresa Brasileira de Pesquisa Agropecuária (EMBRAPA, Goiania, Brazil) (de Morais et al. 2005). It is a semi-early maturing, drought-tolerant cultivar with an average yield under upland conditions of $4,465 \mathrm{~kg} / \mathrm{ha}$. This cultivar is characterized by long fine grains with good whole kernel yields, resistance to rice blast and leaf scald, tolerance to acid soils and drought conditions (de Morais et al. 2005). The wild donor parent, $O$. meridionalis $\mathrm{Ng}$, acc. W2112 (MER) (Oryzabase: http://www.shigen.nig.ac.jp/rice/oryzabaseV4/) was collected in Cooktown, Australia, by Gérard Second, IRD, Montpellier. It shows strong dormancy, seed shattering, photoperiod sensitivity and good tillering proliferation (results not shown). The wild donor $O$. rufipogon Griff. acc. IRGC 105491 (RUF) (International Rice Research Institute, IRRI; http://www. irgcis.irri.org:81/grc/IRGCISHome.html) was collected in Kelantan, Malaysia. This wild accession shows high seedling vigor, good germination rates, good tiller proliferation, and upright grow habit (results not shown). Hereafter, the Curinga $\times O$. meridionalis population will be referred to as $C U R / M E R$ and the Curinga $\times O$. rufipogon population will be referred to as $C U R / R U F$. 
Linkage map construction

Two genetic maps were developed using $110 \mathrm{BC}_{1} \mathrm{~F}_{1}$ $C U R / M E R$ plants genotyped with 122 simple sequence repeat markers (SSR), and $80 \mathrm{BC}_{1} \mathrm{~F}_{1} C U R /$ $R U F$ plants genotyped with 131 SSR markers (Orjuela et al. 2009). The genetic linkage maps were generated using the software MapDisto v.1.7.5 (Lorieux 2012; http://mapdisto.free.fr/MapDisto/). Markers were placed into linkage groups using a logarithm of odds (LOD) probability that two markers are linked versus non-linked of 3.0 and a maximum recombination fraction $\left(r_{\max }\right)$ of 0.3. Marker order in linkage groups was determined using a combination of the 'Order,' 'Ripple' and 'Check inversions' commands. Data errors were then corrected using the 'Color Genotypes' module in MapDisto. Recombination fractions were transformed to estimate map distance using the Kosambi mapping function (Kosambi 1943; Lorieux 2012). A Chi-square test $\left(\chi^{2}\right)$ was carried out for each marker to test deviations of genotypic classes from the expected Mendelian inheritance ratios of 1:1 $(p<0.01)$. The 'Compare maps' command was used to graphically compare colinearity between the generated linkage maps with physical distances from the Michigan State University (MSU) version 7 Rice Genome assembly (http://rice.plantbiology.msu.edu/).

Development of introgression lines (ILs)

Using marker-assisted backcrossing (MABC) two IL libraries were developed. Fixed lines were selected after three rounds of MABC and one generation of double haploidization (DH) using anther culture (Lentini et al. 1995) (Online resource 1). A set of 32 and 48 fixed lines were selected to comprise the $C U R /$ $M E R$ and $C U R / R U F$ populations, respectively. Between each crossing cycle (Sarkarung 1991), SSRs (McCouch et al. 2002, http://www.gramene.org) comprising the Universal Core Genetic Map (UCGM) (Orjuela et al. 2009) and transposable-element-based (TE) indel markers were used to perform foreground and background selection (Hospital et al. 1997). In total, $32 C U R / M E R$ lines were genotyped with 122 SSRs and nine TE-based markers and $48 C U R / R U F$ lines were screened with 131 SSRs as the basis for selecting the IL libraries. Separate sets of markers were used on the two populations due to differences in polymorphism between the parents. Genotypic selection was implemented using CSSL Finder v. 0.9
(Lorieux 2005; http://mapdisto.free.fr/CSSLFinder/) which enables selecting the minimum set of lines to cover the entire donor genome with a desired number and size of included introgressions, small overlaps between consecutive introgressed fragments, and minimal background genome recovery. Genotyping by sequencing (GBS, Elshire et al. 2011) was conducted in the final generation $\left(\mathrm{BC}_{3} \mathrm{~F}_{1}-\mathrm{DH}\right)$.

Double haploid protocol

DH plants were generated as described by Lentini et al. (1995). Seeds were sown in germination trays and grown in the greenhouse for 20-25 days. Seedlings were then transplanted to the field and spaceplanted at $30 \times 40 \mathrm{~cm}$ between plants and rows, and grown under standard flooded (paddy) conditions. At booting stage ( $\sim 60-70$ days after sowing, depending on the genotype), when only 5-8 $\mathrm{cm}$ of the emerging panicle (boot) was visible above the sheath, 3-5 immature panicles (still wrapped in the sheath) were harvested from each plant and kept in polyethylene bags in the dark for 7 days at $10 \pm 2{ }^{\circ} \mathrm{C}$ before culturing.

Panicles were surfaced-sterilized using sterile distilled water and $70 \%$ ethanol. Spikelets from the second third of the panicle were then removed from the sheath leaf, soaked for $3 \mathrm{~min}$ in $10 \%$ commercial bleach $(5.25 \% \mathrm{NaOCl})$, mixed with three drops of Tween 80, and rinsed with sterile distilled water. Each flower was cut at the base, at the anther filament, and grouped into clusters of 10-15 cut flowers. Each cluster was picked with forceps, and the anthers were released by tapping the forceps on the edge of the culture jar (7 cm high $\times 4 \mathrm{~cm}$ diameter). For each jar, $\sim 250$ anthers per $10 \mathrm{ml}$ of liquid callus induction medium were cultured. Jars were sealed with Magenta-B caps and kept in the dark at $25 \pm 1{ }^{\circ} \mathrm{C}$ during 4-6 weeks. Ten embryogenic calli of approximately $1-2 \mathrm{~mm}$ in diameter were transferred onto $60 \mathrm{ml}$ regeneration medium contained in $12 \mathrm{~cm}$ high $\times 9$ $\mathrm{cm}$ diameter glass jars. Jars were sealed with a plastic cap and placed under indirect light for one week and then moved to $80 \mu \mathrm{E} / \mathrm{m}^{2} / \mathrm{s}$ and $16 \mathrm{~h}$ photoperiod. Temperature was kept steady at $25 \pm 1{ }^{\circ} \mathrm{C}$. After 4-6 weeks, green regenerated plants with fully developed roots were transplanted to sterile soil in the greenhouse for 3-4 weeks and then moved to the field. Haploid, DH or diploid, and polyploid plants were 
identified by evaluating plant morphology and fertility. The type-A basal callus induction media, and the components and quantities of plant regeneration media used to generate the DH plants were as described by Lentini et al. (1995).

\section{SSR marker analysis}

Fresh leaf tissue was collected during each generation, and genomic DNA was extracted using a CTAB protocol described by Romero et al. (2014). DNA concentration and quality were evaluated on $0.8 \%$ agarose gels stained with ethidium bromide. The two subsets of SSR from the UCGM set were used in genotyping. Polymerase chain reactions (PCR) were performed using $20 \mathrm{ng}$ of DNA as template, $100 \mathrm{mM}$ Tris-HCL, $500 \mathrm{mM}$ KCL, $0.1 \%$ Triton X-100, 2 ng/ $\mu 1 \mathrm{MgCl}_{2}(25 \mu \mathrm{m}), 0.3 \mu \mathrm{M}$ of each dNTP and primer, and $1 \mathrm{U}$ of Taq DNA polymerase. The reactants were initially denaturated at $94{ }^{\circ} \mathrm{C}$ for $3 \mathrm{~min}$, followed by 30 cycles at $94{ }^{\circ} \mathrm{C}$ for $30 \mathrm{~s}, 30$ cycles at $50-67{ }^{\circ} \mathrm{C}$ (depending on annealing temperature of each primer pair) for $45 \mathrm{~s}, 72{ }^{\circ} \mathrm{C}$ for $1 \mathrm{~min}$, and a final extension at $72{ }^{\circ} \mathrm{C}$ for $5 \mathrm{~min}$. PCR amplified fragments were analyzed using $4 \%$ agarose gels stained with ethidium bromide or $6 \%$ denaturing acrylamide gels stained with silver staining (Panaud et al. 1996).

GBS library preparation and data analysis

Total genomic DNA was extracted from each IL and parents using the Qiagen DNeasy kit (http://www. qiagen.com/). 96-plex libraries were prepared according to Elshire et al. (2011). A custom-designed pipeline described by Spindel et al. (2013) that combines the built-in TASSEL (Bradbury et al. 2007; http://www.maizegenetics.net/\#!tassel/c17q9) SNP caller and the sequence aligner algorithm from PANATI with the genotype imputation algorithm GBS-PLAID-2 was used for data analysis.

\section{Custom Infinium 6K SNP assay and data analysis}

GBS single-nucleotide polymorphism (SNP) calls were confirmed using a custom-designed Infinium HD SNP Assay (M. Wright, Cornell University, pers. comm.; http://www.illumina.com) that detected 1,092 segregating SNPs in the CUR/MER and 1,769 in the $C U R / R U F$ populations using the same DNA extracted for GBS assays. The $6 \mathrm{~K}$ Infinium assay required $750 \mathrm{ng}-1 \mu \mathrm{g}$ of high molecular weight DNA. The DNA was isothermally amplified overnight and a controlled enzyme process fragmented the amplified product. The fragmented DNA was alcohol precipitated and resuspended for hybridization. The BeadChip was prepared for hybridization in a capillary flow-through chamber to which the amplifiedfragmented DNA samples was applied and incubated overnight. During the hybridization step, the DNA annealed to locus-specific SNP markers (50-mers) and the allele specificity was conferred by base extension. The products were fluorescently labeled and intensity was detected and recorded by the Illumina BeadArray reader. Illumina's genome studio software was used for analyzing the genotype calls. Graphical genotypes were drawn using CSSL Finder v.0.9 (Lorieux 2005).

Genetic analysis of pericarp color

Five grains from each of the parents, $C U R, M E R, R U F$, and each IL were de-hulled, photographed and visually scored for pericarp color. Each phenotyped seed was coded $1=$ pigmented pericarp, or $0=$ white pericarp. Two ILs from the CUR/MER and 7 ILs from the CUR/ $R U F$ populations carried the red pericarp and were used to determine whether the $R C$ gene was responsible for the trait. A functional indel marker designed by Sweeney et al. (2006) was used to amplify the 14-bp insertion/deletion in the $R C$ gene (LOC_Os07g11020.1) responsible for white pericarp (forward primer: CTTGCCAGTTTCAGAGAAATCA; reverse primer: CTCTTTCAGCACATGGTTGG). PCR products were amplified from the parents, the 9 ILs with red pericarp, 8 ILs with white pericarp (selected at random from the 71 white seeded ILs), and control white-pericarp varieties, IR64 (ssp indica) and Azucena (ssp tropical japonica). PCR products were visualized using a $4 \%$ agarose gel stained with SYBR ${ }^{\circledR}$ Safe (http://www.lifetechnologies. $\mathrm{com} /$ ), as described by Sweeney et al. (2007).

\section{Upland field evaluation of $C U R / R U F$ ILs}

The recurrent parent, $C U R, 48$ ILs from $C U R / R U F$ population, and 15 elite local checks from the CIAT/ CIRAD (International Center for Tropical Agriculture/Centre de Cooperation Internationale en Research Agronomique) upland rice program were evaluated under upland conditions using two different 
agronomic practices; natural soil conditions $(\mathrm{pH}<$ 5.0) and limed soil conditions $(\mathrm{pH}>5.0)$, at the experimental field station 'La Libertad ICA' (latitude $4^{\circ} 3^{\prime} 40$. $63^{\prime \prime} \mathrm{N}$, longitude $73^{\circ} 27^{\prime} 46.25^{\prime \prime} \mathrm{W}$ ) in Meta, Colombia during Summer 2012. (Note: the RUF donor parent could not be grown in the field due to its classification as a noxious weed. The CUR/MER population was not evaluated in the field because seeds were not available at that time) An alpha lattice design with two replications was used to evaluate the 64 lines distributed in eight blocks, under two treatments: (1) acid soil ( $\mathrm{pH}$ levels $<5$ and aluminum saturation over $75 \%$ ), occur under natural conditions in Meta, and (2) lime treated soil, where soil was amended with 3 tons/ ha of calcium carbonate $\left(\mathrm{CaCO}_{3}\right)$ before planting (Online Resource 2a). Planting was implemented using a six-row planter with a sowing density of $1 \mathrm{~g}$ of seed per linear meter. The plot size was $3 \mathrm{~m}$ wide with two rows per plot, spaced $26 \mathrm{~cm}$ between rows. Fertilizer was applied in two stages. Before planting $80 \mathrm{~kg} / \mathrm{ha}$ of DAP $\left(\mathrm{NH}_{4}\right)_{2} \mathrm{HPO}_{4}, 80 \mathrm{~kg} / \mathrm{ha}$ of $\mathrm{KCl}\left(\mathrm{K}_{2} \mathrm{O}\right), 12 \mathrm{~kg} / \mathrm{ha}$ of $\mathrm{Zn}$, and $75 \mathrm{~kg} / \mathrm{ha}$ of kieserite $\left(\mathrm{MgSO}_{4} \cdot \mathrm{H}_{2} \mathrm{O}\right)$ were applied. After planting one application of $40 \mathrm{~kg} / \mathrm{ha}$ of $\mathrm{KCl}$ and three applications of $26.6 \mathrm{~kg} / \mathrm{ha}$ of urea were added. Weed control was done by applying a postemergence herbicide, Butaclor $3 \mathrm{~L} / \mathrm{ha}$, and Bentazol at $3 \mathrm{~L} / \mathrm{ha}$ plus manual weeding. The fungicide Bim was applied throughout the vegetative cycle as a preventive disease-control measure.

For phenotyping, one linear meter around the center of each plot was marked and plants within that area were harvested. Four agronomic traits: flowering time, plant height, number of tillers, and number of panicles, were evaluated under both treatments. 'Flowering time' was scored as the number of days from planting until $50 \%$ of the plants in the plot have emerged panicles. 'Plant height' was measured using a ruler, as the average length in centimeters from five random tillers in the linear meter from the base of the plant to the tip of the panicle. 'Number of tillers' was defined as the number of tillers from one linear meter harvested from the middle of the plot. "Number of panicles' was defined as the number of panicles from one linear meter harvested from the middle of the plot.

Broad-sense heritability for each trait was estimated using the formula $H^{2}=\delta_{G}^{2} /\left(\delta_{G}^{2}+\left(\frac{\delta_{\mathrm{GE}}^{2}}{e}\right)+\left(\frac{\delta_{e}^{2}}{r e}\right)\right)$ (Hallauer et al. 2010) where $e$ and $r$ are the numbers of environments and replications per environment.
Statistical analysis

To detect significant differences between the recurrent parent CUR and the ILs, a post hoc Dunnett's pairwise multiple comparison test (Dunnett 1980) with a significant level of 0.01 and using CUR as control was performed for each trait. Because most ILs carry more than one segment from the donor parent, a standard single-marker linear regression analysis (SMLRA) was used to identify markers significantly associated with pericarp color, and a stepwise regression analysis ( $\mathrm{Li}$ et al. 2007) was implemented for flowering time, plant height, number of tillers and number of panicles using the software iciMapping v.3.2 (http://www.isbreeding.net/software/?type= detail\&id=13). A likelihood ratio test based on linear regression was used to estimate LOD scores from the $p$ values. A permutation test using 1,000 permutations (Doerge and Churchill 1996) was used to determine the experiment-wise significance threshold at a 0.05 level of significance.

\section{Results}

Development of introgression lines

A marker-assisted backcrossing strategy (MABC) was implemented to develop the two IL libraries. Fixed lines were selected after three rounds of MABC and one generation of double haploidization using anther culture (Lentini et al. 1995) (Online resource 1). A set of 32 and 48 fixed lines were selected to comprise the $C U R / M E R$ and $C U R / R U F$ introgression libraries, respectively (Figs. 1,2). Together, the lines comprising each library contain the majority of the donor genome introgressed as small overlapping chromosome fragments in the $C U R$ genetic background.

A linkage map for each interspecific cross was generated from SSR segregation data in the $\mathrm{BC}_{1} \mathrm{~F}_{1}$ generation to confirm the colinearity of the genomes in $O$. sativa and the distantly related wild donor genomes. The SSR linkage maps also served as the basis for genotypic selection during the first three backcross-generations of IL population development (Online Resource 1). The genetic maps had total distances of $2,005.25 \mathrm{cM} \quad(C U R / M E R)$ and $1,797.57 \mathrm{cM}(C U R / R U F)$ (Online Resource 3a and $3 \mathrm{~b})$. The average distance between markers was 


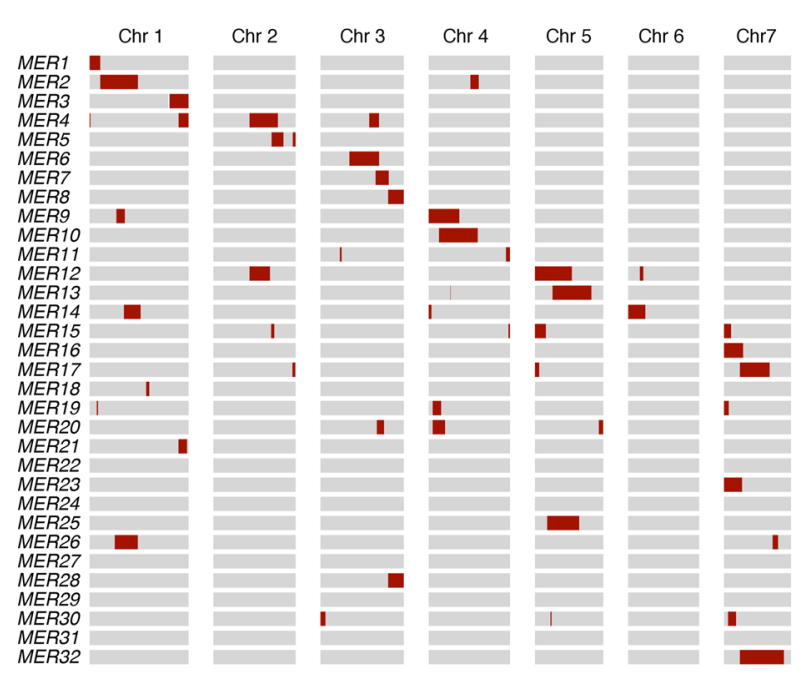

Fig. 1 Graphical genotypes, distribution of target and nontarget introgressions, and genotypic statistics for $32 \mathrm{CUR} / \mathrm{MER}$ ILs. Graphic representation of the genotypic make-up for the recurrent parent CUR (gray), the donor parent MER (red) in the 32 ILs (MER1-MER32) from the bottom to the top of the graph
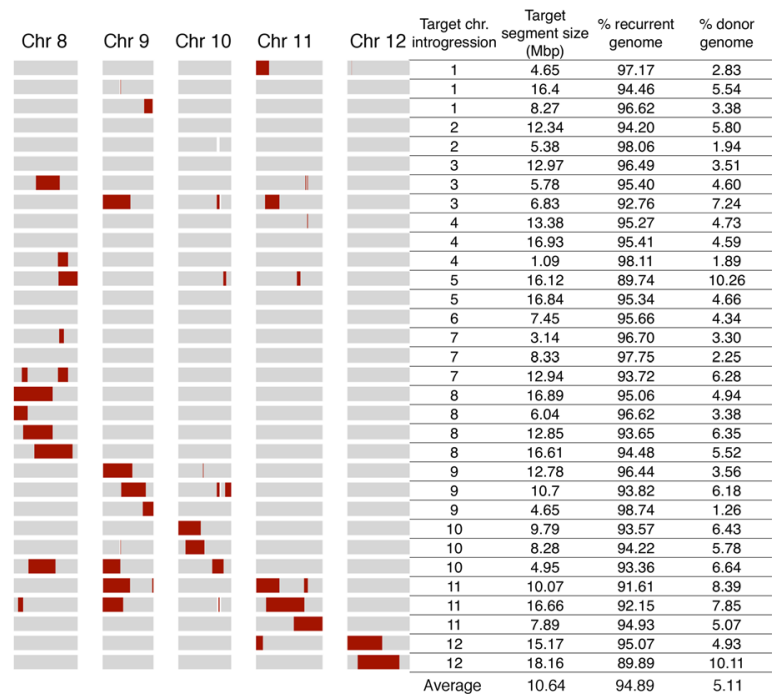

across each of the 12 chromosomes. The chromosome where the target introgression is located, its base-pair size, number of donor segments and percentage of recurrent and donor genome are listed next to each IL. (Color figure online)
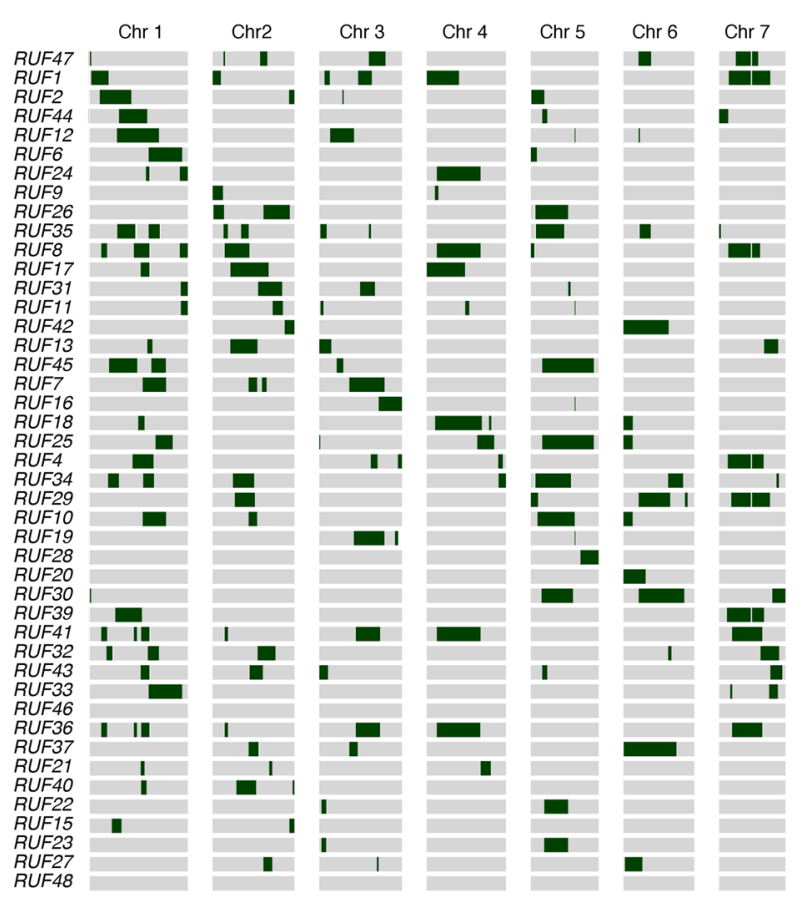

Fig. 2 Graphical genotypes and distribution of target and nontarget introgressions for $40 C U R / R U F$ ILs. Graphic representation of the genotypic make-up for the recurrent parent $C U R$ (gray), the donor parent RUF (green) in 40 ILs (RUF1-RUF48) from the bottom to the top of the graph across each of the 12

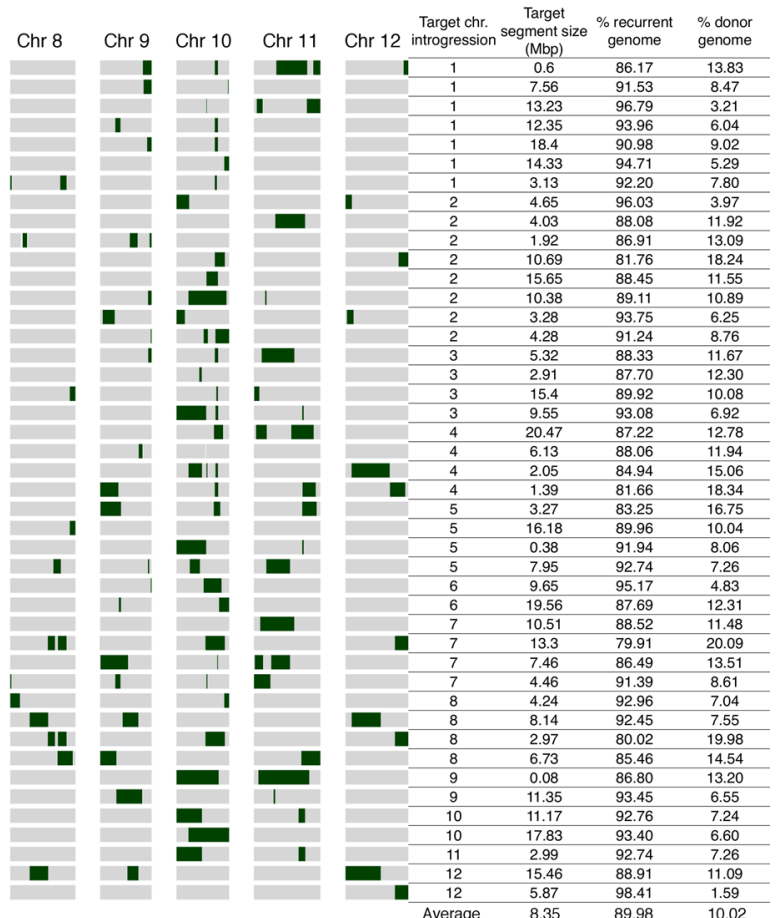

chromosomes. The chromosome where the target introgression is located, its base-pair size, number of donor segments and percentage of recurrent and donor genome are listed next to each IL. (Color figure online) 
$16.41 \mathrm{cM}$ in $C U R / M E R$ and $13.95 \mathrm{cM}$ in $C U R / R U F$ (Online Resource $4 \mathrm{a}$ and $4 \mathrm{~b}$ ). When the positions of markers on the respective genetic maps were compared using pseudo-centimorgans $(1 \mathrm{cM} \sim 240$ $\mathrm{Kbp}$ ), we observed complete colinearity in the two populations (Online Resource 4a and 4b). A Chisquare test for skewed segregation of genotypic classes showed strong deviation $(p<0.01)$ for 18 markers on six chromosomes in the CUR/MER population (Online Resource $5 \mathrm{a}$ and $5 \mathrm{~b}$ ), but no skewed segregation rations were observed in the CUR/ $R U F$ population.

In the $\mathrm{BC}_{3} \mathrm{~F}_{1} \mathrm{DH}$ generation, the two libraries were genotyped using GBS to increase marker density, improve estimation of each recombination break point and to detect donor introgressions that had gone undetected using the sparse coverage provided by the SSR and indel markers (Fig. 3a, b). The number of polymorphic markers identified between $C U R$ and the two wild donors is summarized in Fig. 3a for the SSR/ indels, the 6K SNPs and the GBS markers. Using the 6K SNP assay, marker density increased over tenfold, from an average of $16.41 \mathrm{cM} /$ marker using SSRs to $1.70 \mathrm{cM} /$ marker in the $C U R / M E R$ and from an average of $13.95 \mathrm{cM} /$ marker to $1.03 \mathrm{cM} /$ marker in the $C U R / R U F$ population. Using GBS, marker density increased again, an estimated 50-fold, from an average of $1.70 \mathrm{cM} /$ marker using the $6 \mathrm{~K}$ assay to $0.02 \mathrm{cM} /$ marker in the $C U R / M E R$ and from an average of $1.03 \mathrm{cM} /$ marker using the $6 \mathrm{~K}$ assay to $0.024 \mathrm{cM} /$ marker in the $C U R / R U F$ population. In practical terms, this increase in resolution allowed us to detect additional introgressions that had been missed using SSRs and to better define the size and genome positions of both target and background introgressions in all the ILs as illustrated in Fig. 3b.

In the $C U R / M E R$ IL library, donor introgressions cover $76.73 \%$ of the MER genome. The missing portion of the donor genome $(23.27 \%)$ is distributed in 13 regions across nine different chromosomes (Online Resource 6a). For the $C U R / R U F$, the donor introgressions cover $97.6 \%$ of the $R U F$ genome. The small missing portion of the donor genome $(2.4 \%)$ is distributed in 11 regions across four different

(a)

\begin{tabular}{cccccccc}
\cline { 5 - 8 } $\begin{array}{c}\text { Accession } \\
\text { name }\end{array}$ & Species & Abbreviation & IL library & $\begin{array}{c}\text { Number of } \\
\text { lines }\end{array}$ & SSR & 6K SNP & GBS SNP \\
\hline W2112 & O. rufipogon Griff. & MER & $\begin{array}{c}\text { Curinga/W2112 } \\
\text { (CUR/MER })\end{array}$ & 32 & 122 & 1092 & 107,445 \\
\hline IRGC 105491 & O. meridionalis Ng. & RUF & $\begin{array}{c}\text { Curinga/ } \\
\text { IRGC105491 } \\
\text { (CUR/RUF) }\end{array}$ & 48 & 131 & 1769 & 89,577 \\
\hline
\end{tabular}

(b)

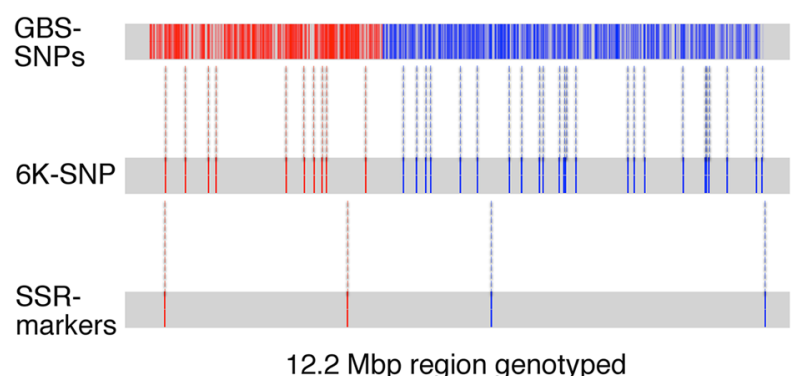

12.2 Mbp region genotyped

Fig. 3 a Polymorphic markers between the recurrent parent $C U R$ and the two donor parents MER and $R U F$, using SSR markers, and SNP-markers from 6K Infinium platform and GBS platform. b Genotyping-platforms comparison. Illustration of a 12.2 Mbp region in chromosome 1 genotyped in two CUR/MER lines, MER3 (on the left) and MER19 (on the right) using SSR

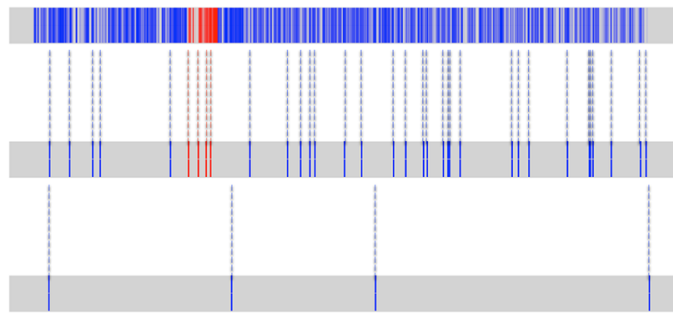

12.2 Mbp region genotyped

markers, a 6K-SNP Infinium chip and GBS. Respectively for each platform 4, 35 and 4,079 markers segregate. The MER alleles are color-coded red, and the CUR alleles are color-coded blue. Comparisons between platforms are determined by dashed lines. (Color figure online) 
chromosomes (Online Resource 6b). The location of each targeted introgressed donor segment, number of donor introgressions and percentage of background donor genome for each ILs are summarized in Figs. 1, 2.

\section{Phenotypic evaluation}

To demonstrate the utility of the IL libraries for mapping and as pre-breeding materials, we evaluated both populations for a simply inherited trait (pericarp color) in the greenhouse, and the $C U R / R U F$ population for four quantitatively inherited traits under upland conditions in the field.

\section{Pericarp color}

The wild donor parents, $M E R$ and $R U F$, both have red pericarp, while $C U R$ has a translucent or white pericarp (Online Resource 7). Two ILs from the CUR/MER library (MER16 and MER23) and seven from the $C U R / R U F$ library (RUF1, RUF4, RUF8, $R U F 29, R U F 36, R U F 39$, and RUF41) were identified with red pericarp color, while all other ILs in both libraries had white pericarp (Fig. 4a, Online Resource 7). When the functional indel marker previously developed by Sweeney et al. (2006) was used to determine which lines carried the wild-type allele and which carried the derived allele at $R C$, both $M E R$ and $R U F$, as well as the two $C U R / M E R$ ILs and the seven $C U R / R U F$ ILs with red pericarp were confirmed to carried the wild-type (non-deletion) allele (Fig. 4b), while the CUR recurrent parent, the eight randomly selected white pericarp ILs and two white-seeded control varieties, IR64 (ssp indica) and Azucena (ssp tropical japonica), all carried the derived (14-bp deletion), recessive allele (Fig. $4 \mathrm{~b}$ and Online Resource 7).

The two red $C U R / M E R$ ILs shared a wild introgression on chromosome 7 in the region containing $R C$, defined by the GBS-SNP markers S7_12945 and S7_7924008 and mapping to the interval 07:12,945-07:7,924,008 bp on the physical map of rice (MSU7.0, Kawahara et al. 2013). To confirm that allelic variation at the $R C$ gene was also predictive of pericarp color in the CUR/RUF ILs, where lines carry multiple donor introgressions in the genetic background, we conducted a SMLRA and identified seven markers significantly associated with pericarp color (LOD > 3.1). All seven SNPs were located on chromosome 7 between positions 07:5,308,81207:18,659,022 bp (MSU7.0, Kawahara et al. 2013) (Fig. 4c). The $R C$ gene is located at 07:6,061,890$6,068,318 \mathrm{bp}$ and is contained in the overlapping segment shared by these lines (Fig. 4a). In both populations, the functional marker in $R C$ is a perfect predictor of pericarp color in our IL libraries.

Upland field evaluation

When the CUR/RUF ILs were evaluated for four agronomic traits in the field, the distribution of 'plant height,' 'tiller number,' and 'panicle number' was normal, while the distribution of 'days to flowering' was skewed toward late flowering (Online Resource 2b). 'Tiller number' and 'panicle number' were strongly correlated ( $r=0.9$ ) (Online Resource 2b). Broad sense heritability $\left(H^{2}\right)$ estimations showed better repeatability for 'days to flowering' $\left(H^{2}=0.97\right)$ and 'plant height' $\left(H^{2}=0.85\right)$ than for 'number of tillers' $\left(H^{2}=0.55\right)$ and 'number of panicles' $\left(H^{2}=0.51\right)$.

Significant differences among IL genotypes $(p<$ $0.05)$ were observed for all traits (Fig. 5). For flowering time, 16 ILs were significantly different from the recurrent parent: two ILs flowered earlier than $C U R$, while 14 ILs flowered later $(p<0.05$; Fig. 5a). Nine ILs were significantly taller than CUR $(p<0.05$; Fig. 5b). Of particular note, IL RUF27 had a significantly higher number of both tillers and panicles per linear meter than CUR ( $p<0.05$; Fig. 5c, d). This IL warrants further testing to determine its relevance as a potential donor in breeding.

When the performance of ILs was compared between plants grown in naturally occurring acid soils and lime-treated (non acid) soils, significant differences were observed for 'days to flowering' and 'plant height,' but not for 'number of tillers' or 'number of panicles' $(p<0.05)$. Overall, plants flowered earlier in acid soils than in limed conditions $(p<0.05)$. A stepwise regression analysis identified a region on chromosome 3 that was significantly associated with 'days to flowering' under both treatments (LOD > 5.53) and one region on chromosome 9 significantly associated with 'days to flowering' under limed soil conditions only (LOD > 5.53; Fig. 6a, b; Online Resource 8a) For plant height, plants under acid soil conditions were, on average, smaller than those under limed conditions. A stepwise regression analysis 
Fig. 4 Chromosome 7 donor introgressions a Chromosome 7 zoom-in. Genotypic introgression of 12 different IL and parents in chromosome 7 , the recurrent genome is colored in gray and the donor genome in red. The phenotype of each IL is shown in the right border b PCR products to detect the functional 14-bp indel marker in the $R c$ locus (Sweeney et al. 2006) from seven colored-pericarp ILs, and four white coloredpericarp, the parents $C U R$, $R U F, M E R$ and two controls lines IR64 and Azucena. c Summary of significant regions associated with pericarp color $($ LOD > 3.1) using logistic regression (SMA-LR) analysis. (Color figure online) (a)

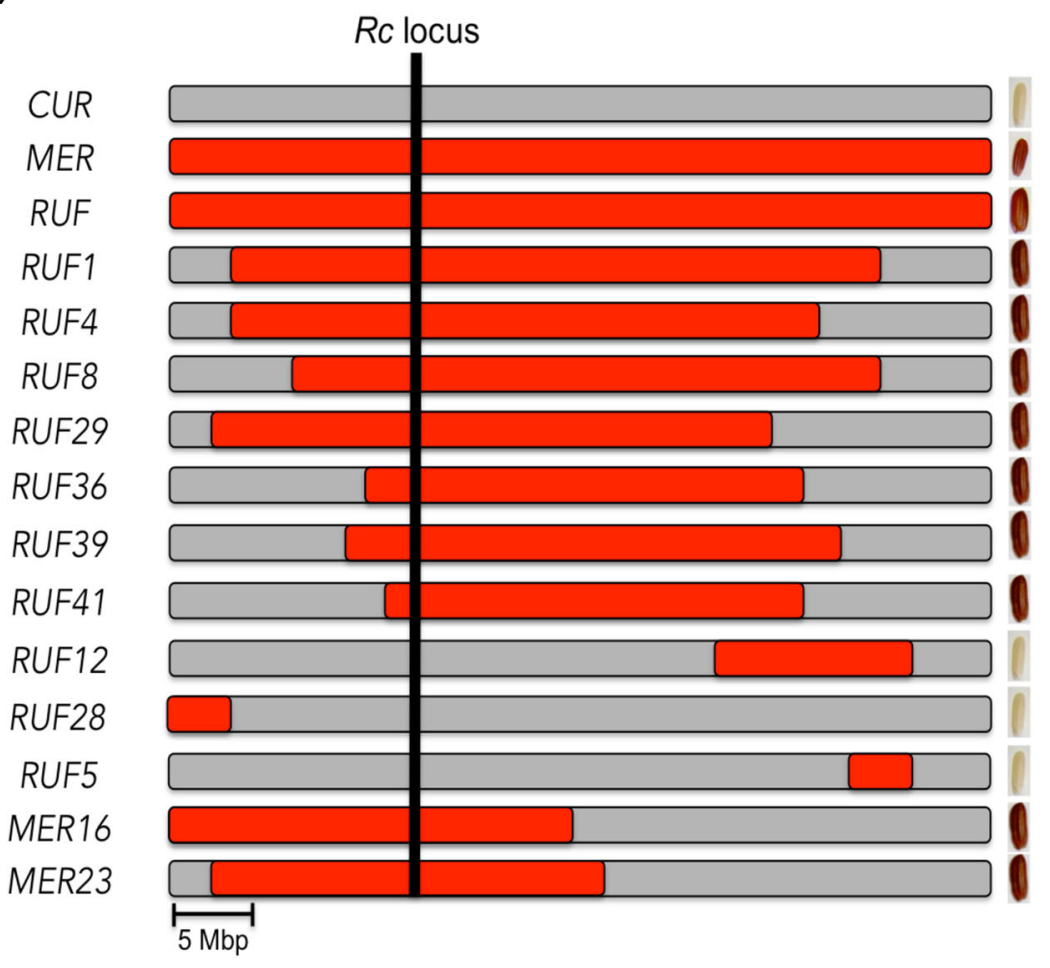

(b)

$R C$ genotypic analysis

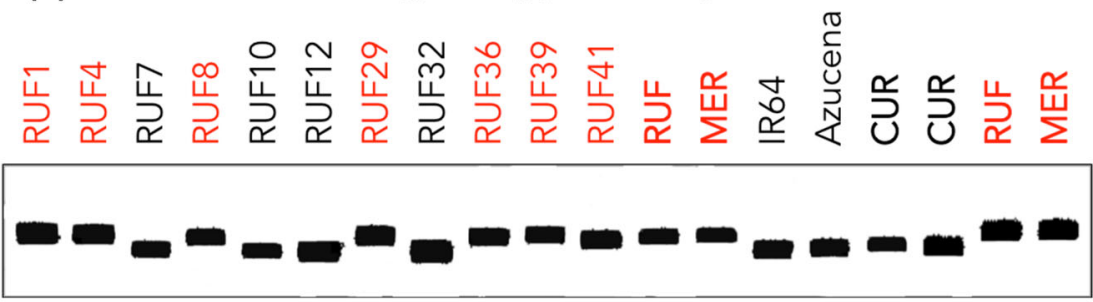

(c)

\begin{tabular}{cccccc}
\hline Population & Chr. & Peak SNPs & $\begin{array}{c}\text { Peak Mb } \\
\text { position }\end{array}$ & Flanking SNPs & $\begin{array}{c}\text { Flanking Mb } \\
\text { position }\end{array}$ \\
\hline \hline CUR/RUF & 7 & $\begin{array}{l}\text { S7_5623759/ } \\
\text { S7_1805445 }\end{array}$ & $5.62-18.05$ & $\begin{array}{l}\text { S7_5308812/ } \\
\text { S7_1866433 }\end{array}$ & $5.3-18.66$ \\
\hline CURMER & 7 & $\begin{array}{l}\text { S7_12945/ } \\
\text { S7_7924008 }\end{array}$ & $0.012-7.92$ & $\begin{array}{l}\text { S7_12945/ } \\
\text { S7_7924008 }\end{array}$ & $0.012-7.92$ \\
\hline
\end{tabular}

identified a region on chromosome 10 that was significantly associated (LOD > 3.51) with 'plant height' under both treatments, and a region on chromosome 1 significantly associated with 'plant height' under natural acid soil conditions (LOD > 3.51; Fig. 6a, b; Online Resource 8b). Based on these examples, we demonstrate that the interspecific ILs developed on this project embody a wide range of phenotypic variation and can be used to dissect the genetics of both simply and quantitatively inherited traits, as well as to broaden the genetic base of elite breeding materials. 

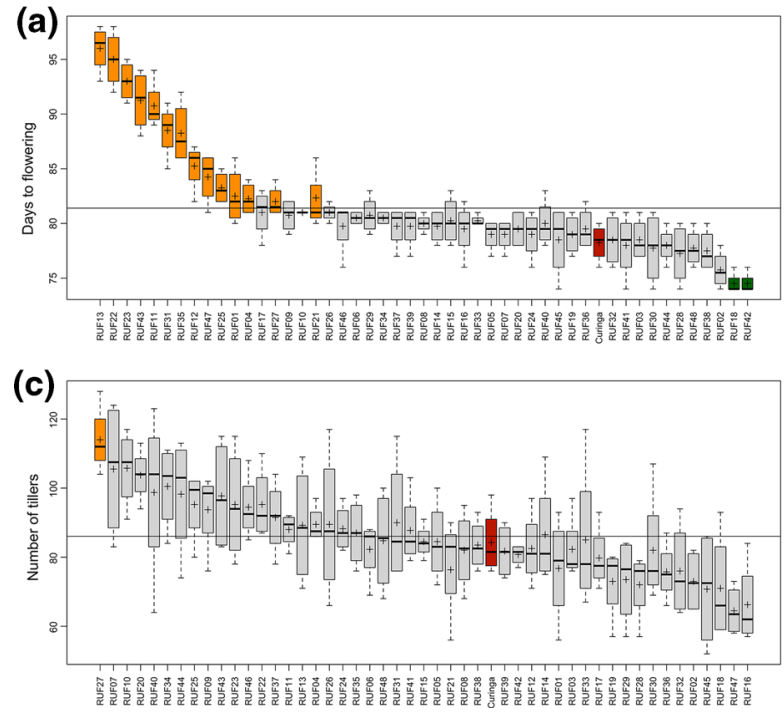

Fig. $5 C U R / R U F$ upland field evaluation Boxplots showing the distribution of $C U R / R U F$ ILs for four phenotypes. In each, the recurrent parent $(C U R)$ is colored red and ILs significantly higher than $C U R(p<0.05)$ are colored orange, and lower than

\section{Discussion}

We report the development of two sets of interspecific ILs using a drought-tolerant tropical japonica cultivar, Curinga $(C U R)$, as the recurrent parent and two wild donor accessions from the species $O$. meridionalis $(M E R)$ and $O$. rufipogon $(R U F)$. We demonstrate that the IL populations segregate for traits of interest, and we identified a superior IL, RUF27, that has a higher number of tillers and number of panicles than $C U R$ under upland soil conditions. This new germplasm offers the rice community an opportunity to explore the genetic potential of variation found in two wild rice species in an elite cultivated background and to identify potentially useful pre-breeding materials.

Genetic divergence of wild and cultivated materials

Despite the fact that the $O$. meridionalis lineage is estimated to have diverged from the other AA genome species approximately $2 \mathrm{M}$ years ago and remains geographically isolated from both $O$. sativa and $O$. rufipogon, we demonstrate that SSR-based linkage maps were collinear in the two interspecific crosses. This made it possible to use the SSR and indel markers for MABC during three generations of backcrossing to

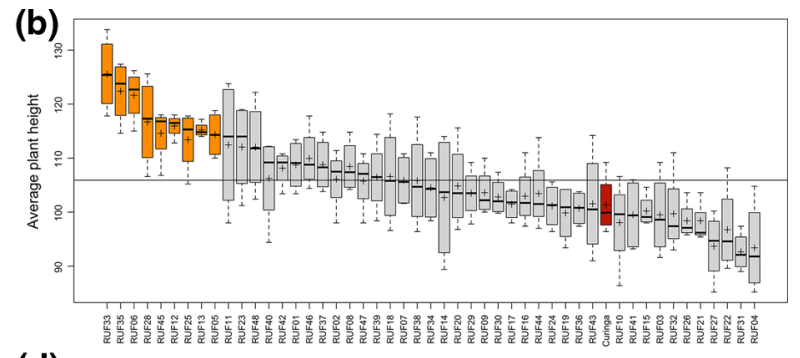

(d)

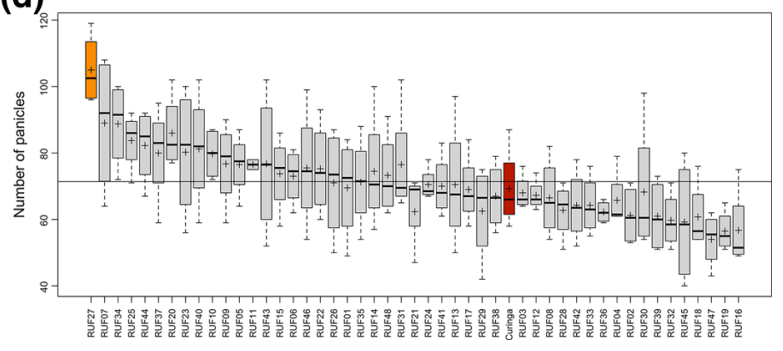

CUR $(p<0.05)$ are colored green. a 'Days to flowering.' b 'Average plant height.' c 'Number of tillers.' d 'Number of panicles'. (Color figure online)

construct the IL populations. Nonetheless, we would expect more structural variation, greater disruption of recombination, and more significant sterility barriers between MER and CUR than between RUF and CUR. Consistent with this hypothesis, $26.3 \%$ of the $M E R$ genome was missing from the IL library reported here, while only $2.4 \%$ of the $R U F$ genome was not represented in the $C U R / R U F$ population. We also observed fewer and smaller introgressed regions, greater segregation distortion, and had more difficulty making crosses in the CUR/MER than in the CUR/ $R U F$ population. Nevertheless, the theoretical percentage of overall recurrent parent genome expected in a random $\mathrm{BC}_{3}$ generation line $(93.75 \%)$ was very similar to that obtained in the CUR/MER IL library (95\%) reported here.

Linkage analysis identified six regions with strong segregation distortion in the CUR/MER map (Online Resource 5). Seven of the fragments that were lost during the development of the CUR/MER ILs colocalized with markers showing strong segregation distortion in the $\mathrm{BC}_{1} \mathrm{~F}_{1}$ (Online Resource 6a). In addition four of the regions associated with segregation distortion in these materials, on chromosomes 4 , 6, 11, and 12 (Online Resource 5), co-localized with previously reported sterility factors (Kinoshita 1991, 1993; Rha et al. 1995; Matsubara and Khin-Thidar 
Fig. 6 Upland field evaluation summary, a GBS SNP coverage across the CUR/RUF ILs population (black lines in chromosome bars), graphic location of SNPs significantly associated with 'days to flowering' (green lines) and 'plant height' (orange lines), and published QTL regions that co-localize with the associated SNPs from this study (red and blue bars). b Summary of significant regions associated with plant height (LOD > 3.5), and days to flowering (LOD > 5) using a stepwise regression single-marker analysis (SR-SMA) for days to flowering and plant height. (Color figure online)
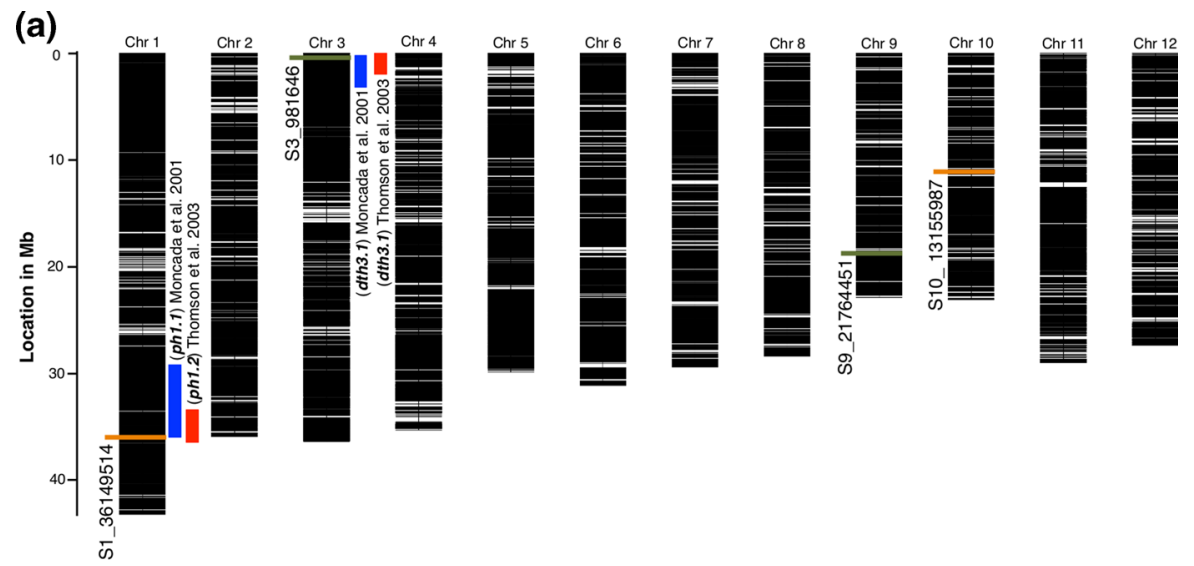

(b)

\begin{tabular}{|c|c|c|c|c|c|c|c|}
\hline Trait & Environment & Chr. & $\begin{array}{l}\text { Position } \\
\text { (Mb) }\end{array}$ & SNP & LOD & $\begin{array}{l}\text { Additive } \\
\text { effects }\end{array}$ & $\begin{array}{l}\text { Published QTL } \\
\text { (reference) }\end{array}$ \\
\hline $\begin{array}{l}\text { Plant } \\
\text { Height }\end{array}$ & $E-1$ & 1 & 36.1 & S1_36149514 & 4.44 & 9.16 & $\begin{array}{c}\text { ph1.1 Moncada } \\
\text { et al. } 2001 \text { (1) } \\
\text { ph1.2 Xiao et al. } \\
1998(2)\end{array}$ \\
\hline $\begin{array}{l}\text { Plant } \\
\text { Height }\end{array}$ & $\begin{array}{c}\text { Mean E-1 and } \\
\text { E2 }\end{array}$ & 1 & 36.1 & S1_36149514 & 4.45 & 8.3 & $\begin{array}{c}\text { ph1.1 Moncada } \\
\text { et al. } 2001(1) \\
\text { ph1.2 Xiao et al. } \\
1998(2)\end{array}$ \\
\hline $\begin{array}{l}\text { Plant } \\
\text { Height }\end{array}$ & $E-1$ & 10 & 13.15 & S10_ 13155987 & 4.08 & -3.38 & None \\
\hline $\begin{array}{l}\text { Plant } \\
\text { Height }\end{array}$ & $E-2$ & 10 & 13.15 & S10_ 13155987 & 3.61 & -4.24 & None \\
\hline $\begin{array}{l}\text { Plant } \\
\text { Height }\end{array}$ & $\begin{array}{c}\text { Mean E-1 and } \\
\text { E2 }\end{array}$ & 10 & 13.15 & S10_13155987 & 4.68 & -3.55 & None \\
\hline $\begin{array}{l}\text { Days to } \\
\text { flowering }\end{array}$ & $E-1$ & 3 & 0.9 & S3_981646 & 16.86 & 6.3 & $\begin{array}{l}\text { dth3.1 Moncada } \\
\text { et al. } 2001 \text { (3) } \\
\text { dth3.1 Thomson } \\
\text { et al. } 2003 \text { (4) }\end{array}$ \\
\hline $\begin{array}{l}\text { Days to } \\
\text { flowering }\end{array}$ & $E-2$ & 3 & 0.9 & S3_981646 & 17.78 & 5.9 & $\begin{array}{l}\text { dth3.1 Moncada } \\
\text { et al. } 2001 \text { (3) } \\
\text { dth3.1 Thomson } \\
\text { et al. } 2003 \text { (4) }\end{array}$ \\
\hline $\begin{array}{l}\text { Days to } \\
\text { flowering }\end{array}$ & $\begin{array}{c}\text { Mean } E-1 \text { and } \\
E-2\end{array}$ & 3 & 0.9 & S3_981646 & 18.47 & 6.11 & $\begin{array}{l}\text { dth3.1 Moncada } \\
\text { et al. } 2001 \text { (3) } \\
\text { dth3.1 Thomson } \\
\text { et al. } 2003 \text { (4) }\end{array}$ \\
\hline $\begin{array}{l}\text { Days to } \\
\text { flowering }\end{array}$ & $E-2$ & 9 & 21.76 & S9_21764451 & 7.48 & 2.88 & None \\
\hline $\begin{array}{l}\text { Days to } \\
\text { flowering }\end{array}$ & $\begin{array}{c}\text { Mean E-1 and } \\
\text { E-2 }\end{array}$ & 9 & 21.76 & S9_21764451 & 6.77 & 2.66 & None \\
\hline $\begin{array}{c}\text { Number of } \\
\text { tillers }\end{array}$ & \multicolumn{7}{|c|}{ "No significant QTLs detected" } \\
\hline $\begin{array}{l}\text { Number of } \\
\text { panicles }\end{array}$ & \multicolumn{7}{|c|}{ "No significant QTLs detected" } \\
\hline
\end{tabular}

2003). Deviation from expected Mendelian segregation ratios is commonly observed in interspecific crosses of rice (McCouch et al. 1988; Xu et al. 1997; Lorieux et al. 2000; Brondani et al. 2001) and is usually associated with the presence of linked sterility factors and post-zygotic reproductive barriers (Sano 1990; Koide et al. 2008; Garavito et al. 2010; Gutierrez et al. 2010).
It is noteworthy that many of the missing $M E R$ fragments in the $C U R / M E R$ ILs were lost during the double haploidization process, rather than during the backcrossing. This suggests a possible sex-dependent transmission-ratio distortion system acting at these loci, such that there was preferential abortion of male gametes possessing the MER alleles in favor of those with the CUR alleles. Another reason why specific 
donor segments may be underrepresented or lost from the CUR/MER IL population is that they were negatively associated with regeneration ability during the tissue culture process (Xu et al. 1997). Li et al. (2013) identified 25 QTLs associated with tissue culture response from an intraspecific cross between the indica variety 93-11 and the japonica variety Nipponbare. Many of the QTLs associated with regeneration ability in tissue culture in chromosome 2 ( $q C B T-2 a, q C B T-2 b$, and $q R R-7$ ), and 6 ( $q I C C-6$ and $q I C F-6)$ (Li et al. 2013) colocalize with missing regions in the $C U R / M E R$ ILs.

In contrast to the $C U R / M E R$ population, segments covering almost the entire $R U F$ genome were successfully transmitted to the $C U R / R U F$ IL library. However, the recovery of the recurrent parent genome $(89.9 \%)$ was lower than expected $(93.75 \%)$. This is partly due to the low genomic coverage with SSRs, and possibly because the populations used for selection during the cycles of MABC were not large enough to enable us to identify the most desirable combination of target introgression(s) and clean genetic background.

Utility of GBS for enhancing marker density

Currently, GBS is being adopted as an alternative to the use of fixed SNP arrays for the generation of highdensity marker data in plant breeding and genetics. This is largely due to the simplification and automation of library preparation production protocols, the high throughput and relatively low cost of sequencing, the ability to simultaneously discover and genotype SNPs, and the reduction in ascertainment bias (Heslot et al. 2013). However, the versatility and potential for widespread use of GBS depends upon the bioinformatics tools available to address the relatively high error rate and the data sparsity of GBS. Several bioinformatics pipelines have been developed to overcome these obstacles (Bradbury et al. 2007; Spindel et al. 2013; Sonah et al. 2013). By using GBS, we were able to increase our maker density over 50-fold, compared to a fixed 6K SNP array, and over 600-fold compared to our initial SSR dataset. The ability to rapidly generate high-density SNP datasets in fixed collections of ILs, such as those developed in this study, makes it possible to define the size and positions of both target and background introgressions and to identify small donor introgressions that had been missed using previous, lower density marker datasets.

Phenotypic variation

Wild species are differentiated from cultivated forms of rice by numerous genetic changes and trait variation, including pigmentation of the pericarp. Most wild species, including both $O$. meridionalis and $O$. rufipogon, have red pericarp, while in $O$. sativa cultivars, the pericarp is white or translucent. The $R C$ gene responsible for the change from red to white pericarp is a basic helix-loop-helix transcription factor, and a 14-bp deletion in exon 6 of the $R C$ gene is responsible for the loss of pigmentation in the pericarp tissue (Sweeney et al. 2006). The $R C$ gene maps within the introgressed region on chromosome 7 that is associated with red pericarp in the $C U R / M E R$ and $C U R / R U F$ populations (Fig. 4). Here, we demonstrated that ILs with colored pericarp carry an introgression from the donor parent at the $R C$ locus (Online Resource 7). Genotypic screening using the functional marker in the $R C$ gene confirmed that all the lines with colored pericarp carry at least one wild-type allele at $R C$, compared with control lines that have white pericarp and are known to carry the 14-bp deletion in Exon 6 of $R C$ (Fig. 4b). These results confirmed our mapping results and demonstrated that the colored phenotype for both IL libraries is associated with the $R C$ gene. Proanthocyanidins, the red pigment in rice pericarp, have been associated with some nutritional benefits (Ling et al. 2001) that could be exploited by developing niche markets. ILs identified in this study with red pericarp might be of interest for breeding programs interested in developing value-added rice varieties. Some of the redpericarp ILs identified in this study carry a single, small, well-defined wild introgression at the $R C$ locus on chromosome 7 , and the genomic composition of the other ILs is close to $97 \%$ of the RP having all of the agronomic traits of $C U R$ and only a small introgression that causes the colored pericarp phenotype.

Upland rice is grown in rainfed, naturally welldrained soils without surface water accumulation (Ahmadi et al. 2004). This agro-ecosystem is particularly prone to stresses such as aluminum toxicity, phosphorus deficiency, drought caused by erratic rainfall, rice blast disease and weeds (Ahmadi et al. 2004). The genetic base of upland rice cultivars in 
Latin America is particularly narrow due to the fact that a small core of adapted progenitors has been used repeatedly in different rice breeding programs (Guimaraes 1993; Guimaraees et al. 1996). It is therefore important to identify novel allelic variation that can improve the genetic pool of upland varieties. To assess the potential for phenotypic variation among the interspecific ILs developed on this project, we evaluated the $48 C U R / R U F$ ILs for four agronomic traits, 'Days to flowering,' 'Plant height,' 'Tiller number' and 'Panicle number' under upland soil conditions in Meta-Colombia.

While variation coming from the wild donor was often associated with traits that were not considered favorable in the context of plant improvement, the reverse was also true. Thus, an $O$. rufipogon introgression on the short arm of chromosome 3 was associated with late flowering (Fig. 6a, b), consistent with reports using the same wild donor in the cv Jefferson (tropical japonica) genetic background (Xiao et al. 1998; Moncada et al. 2001; Thomson et al. 2003). The HEADING DATE 9 (Hd9) locus, known to be involved in photoperiod sensitivity, is located in this region (Lin et al. 2002). On average the lines with the $R U F$ introgression at the $H d 9$ locus flowered 15.5 days later than CUR. The MADS-box gene OsSOCl is located within the $H d 9$ interval (chromosome 3: 1,269,856-1,271,783) (Tadege et al. 2003) and is a candidate gene that may be responsible for the late flowering phenotype of ILs carrying the $R U F$ allele at this locus. On chromosome 1, a $R U F$ introgression increased the height of ILs under natural acid soil conditions. This region co-localizes with the plant height QTLs, ph1.1 (Moncada et al. 2001) and ph1.2 (Thomson et al. 2003) (Fig. 6a, b), and contains the SEMI-DWARF1 (SDI) gene associated with the green revolution (Sasaki et al. 2002). The identification of RUF introgressions associated with late flowering and taller plant height represent throw backs to ancestral traits, while plant breeders have consciously selected for shorter plants with early flowering traits for production in upland ecosystems in South America (Châtel et al. 2008).

On the other hand, a RUF introgression on chromosome 10 was associated with reduced plant height under both limed and natural acid soil conditions. This $R U F$ allele contributes transgressive variation for shorter stature that may be of interest to breeders interested in selecting for shorter plants. Similarly, the
IL $R U F 27$ produced more tillers and more panicles than the recurrent parent, $C U R$, while it did not differ in days to flowering or plant height. RUF27 also had the highest grain yield of any of the ILs in this study, though the difference between $R F U 27$ and $C U R$ was not statistically significant. RUF 27 carries six small introgressions on chromosomes 2, 6, 8, 9, 10 and 12 and it will be interesting to continue backcrossing this line to understand the genetics underlying the higher number of tillers and panicles and to validate the value of this IL for breeding purposes. Further, phenotypic analysis is underway on both populations of ILs under a variety of field and controlled environment conditions to better characterize these lines and their utility as pre-breeding materials.

The ILs described here are available for research purposes via a Material Transfer Agreement from CIAT.

Acknowledgments We gratefully acknowledge financial support for the PhD fellowship of JDA from the Monsanto Beachell-Bourlag International Scholars Program, and financial support that made this research possible from the Generation Challenge Program (award \# G3005.10 to ML and SMc); CIRAD-CIAT rice collaborative project (to CG); USDA -AFRI award \#002010 to SMc; NSF-PGRP award \#1026555. This work was undertaken as part of the initiative 'Adapting Agriculture to Climate Change: Collecting, Protecting and Preparing Crop Wild Relatives' which is supported by the Government of Norway. The project is managed by the Global Crop Diversity Trust with the Millennium Seed Bank of the Royal Botanic Gardens, Kew and implemented in partnership with national and international gene banks and plant breeding institutes around the world. For further information see the project website: http://www.cwrdiversity.org/. We are also grateful to Fumio (Gen) Onishi from Cornell University, Francisco Rodriguez Cruz, Marcos Brito, and Jaime Bocanegra from CIAT for technical support, and to Jeanne Kisacky for help formatting.

Open Access This article is distributed under the terms of the Creative Commons Attribution License which permits any use, distribution, and reproduction in any medium, provided the original author(s) and the source are credited.

\section{References}

Ahmadi N, Dzido JL, Vales M, Rakotoarisoa J, Chabanne A (2004) Upland rice for highlands: new varieties and sustainable cropping systems for food security promising prospects for the global challenges of rice production. In: Proceedings of the FAO rice conference: rice is life. International Rice Commission Newsletter. pp 58-65 
Ali ML, Sanchez PL, Yu S, Lorieux M, Eizenga GC (2010) Chromosome segment substitution lines: a powerful tool for the introgression of valuable genes from Oryza wild species into cultivated rice (O. sativa). Rice 3:218-234. doi:10.1007/s12284-010-9058-3

Ando T, Yamamoto T, Shimizu T, Ma XF, Shomura A, Takeuchi Y, Lin SY, Yano M (2008) Genetic dissection and pyramiding of quantitative traits for panicle architecture by using chromosomal segment substitution lines in rice. Theor Appl Genet 116:881-890. doi:10.1007/s00122008-0722-6

Asano K, Yamasaki M, Takuno S, Miura K, Katagiri S, Ito T, Doi K, Wu J, Ebana K, Matsumoto T, Innan H, Kitano H, Ashikari M, Matsuoka M (2011) Artificial selection for a green revolution gene during japonica rice domestication. Proc Natl Acad Sci. doi:10.1073/pnas.1019490108

Asíns MJ (2002) Present and future of quantitative trait locus analysis in plant breeding. Plant Breeding 121:281-291. doi:10.1046/j.1439-0523.2002.730285.x

Bouman BAM, Barker R, Humphreys E, Tuong TP, Atlin GN, Bennett J, Dawe D, Dittert K, Dobermann A, Facon T, Fujimoto N, Gupta RK, Haefele SM, Hosen Y, Ismail AM, Johnson D, Johnson S, Khan S, Lin S, Masih I, Matsuno Y, Pandey S, Peng S, Thiyagarajan TM, Wassman R (2007) Rice: feeding the billions. In: Water for food, water for life: a comprehensive assessment of water management in agriculture. IWMI, Colombo, pp 515-549

Bradbury PJ, Zhang Z, Kroon DE, Casstevens TM, Ramdoss Y, Buckler ES (2007) TASSEL: software for association mapping of complex traits in diverse samples. Bioinformatics 23:2633-2635. doi:10.1093/bioinformatics/btm308

Brar DS, Khush GS (1997) Alien introgression in rice. Plant Mol Biol 35:35-47

Brondani C, Brondani R, Rangel P, Ferreira M (2001) Development and mapping of Oryza glumaepatula-derived microsatellite markers in the interspecific cross Oryza glumaepatula $\times O$ sativa. Hereditas 134:59-71

Châtel M, Ospina Y, Rodriguez F, Lozano VH, Delgado H (2008) Upland rice composite population breeding and selection of promising lines for Colombian savannah ecosystem. Pesqui Agropecu Trop (Agric Res Trop) 38:1-5

Chin JH, Gamuyao R, Dalid C, Bustamam M, Prasetiyono J, Moeljopawiro S, Wissuwa M, Heuer S (2011) Developing rice with high yield under phosphorus deficiency: Pupl sequence to application. Plant Physiol 156:1202-1216. doi:10.1104/pp.111.175471

Collard BCY, Mackill DJ (2008) Marker-assisted selection: an approach for precision plant breeding in the twenty-first century. Philos Trans R Soc Lond B Biol Sci 363:557-572. doi:10.1098/rstb.2007.2170

de Morais O, da Castro EM, Soares AA, Guimarães EP, Chatel M, Ospina Y, de Lopes AM, de Pereira JA, Utumi MM, Centeno AC, Fonseca R, Breseghello F, Guimaraes CM, Bassinello PZ, Sitarama Prabhu A, Ferreira E, Gervini de Souza NR, Alves de Souza M, Sousa Reis M, Guimaraes Santos P (2005) BRSMG Curinga: cultivar de arroz de terras altas de ampla adaptacicão para o Brasil. Embrapa Arroz e Feijão. Comunicado Técnico 114:1-8

Doerge RW, Churchill GA (1996) Permutation tests for multiple loci affecting a quantitative character. Genetics 142:285-294
Doi K, Sobrizal, Ikeda K, Sanchez P., Kurakazu T, Nagai Y, Yoshimura A (2003) Developing and evaluating rice chromosome segment substitution lines. IRRI, Rice science: innovations and impact for livelihood, pp 289-296

Dunnett CW (1980) Pairwise multiple comparisons in the homogeneous variance, unequal sample size case. J Am Stat Assoc 75:789-795. doi:10.1080/01621459.1980.10477551

Ebitani T, Takeushi Y, Nonoue Y, Yamamoto T, Takeuchi K, Yano M (2005) Chromosome segment substitution lines carrying overlapping chromosome segments of indica rice cultivar "Kasalath" in a genetic background of japonica elite cultivar "Koshihikari." Breed Sci 55(1):65-73

Elshire RJ, Glaubitz JC, Sun Q, Poland JA, Kawamoto K, Buckler ES, Mitchell SE (2011) A robust, simple genotyping-by-sequencing (GBS) approach for high diversity species. PLoS ONE 6:e19379. doi:10.1371/journal.pone. 0019379

Food and Agricultural Organization of the United Nations (2003) The international year of rice 2004: concept paper. pp 1-24

Gao L-Z, Zhang C-H, Li D-Y, Pan D-J, Jia J-Z, Dong Y-S (2006) Genetic diversity within Oryza rufipogon germplasms preserved in Chinese field gene banks of wild rice as revealed by microsatellite markers. Biodivers Conserv 15:4059-4077. doi:10.1007/s10531-005-3135-8

Garavito A, Guyot R, Lozano J, Gavory F, Samain S, Panaud O, Tohme J, Ghesquiere A, Lorieux M (2010) A genetic model for the female sterility barrier between asian and african cultivated rice species. Genetics. doi:10.1534/ genetics. 110.116772

Godfray HCJ, Beddington JR, Crute IR, Haddad L, Lawrence D, Muir JF, Pretty J, Robinson S, Thomas SM, Toulmin C (2010) Food security: the challenge of feeding 9 billion people. Science 327:812-818. doi:10.1126/science. 1185383

Gu X-Y, Foley ME, Horvath DP, Anderson JV, Feng J, Zhang L, Mowry CR, Ye H, Suttle JC, Kadowaki K, Chen Z (2011) Association between seed dormancy and pericarp color is controlled by a pleiotropic gene that regulates abscisic acid and flavonoid synthesis in weedy red rice. Genetics 189:1515-1524. doi:10.1534/genetics.111.131169

Guimaraes EP (1993) Genealogy of Brazilian upland rice varieties. Int Rice Res Notes 18:6

Guimaraees EP, Borrero J, Ospina-Rey Y (1996) Genetic diversity of upland rice germplasm distributed in Latin America. Pesqu Agropecu Bras 31:187-194

Gutierrez A, Carabali J, Giraldo O, Martinez C, Correa F, Prado G, Tohme J, Lorieux M (2010) Identification of a rice stripe necrosis virus resistance locus and yield component QTLs using Oryza sativa $\times$ O. glaberrima introgression lines. BMC Plant Biol 10:6. doi:10.1186/1471-2229-10-6

Hallauer AR, Carena MJ, Miranda Filho J (2010) Quantitative genetics in maize breeding. Springer, Berlin

Heslot N, Rutkoski J, Poland J, Jannink J-L, Sorrells ME (2013) Impact of marker ascertainment bias on genomic selection accuracy and estimates of genetic diversity. PLoS ONE 8:e74612. doi:10.1371/journal.pone.0074612

Hospital F, Moreau L, Lacoudre F, Charcosset A, Gallais A (1997) More on the efficiency of marker-assisted selection. Theor Appl Genet 95:1181-1189. doi:10.1007/ s001220050679 
Imai I, Kimball J, Conway B, Yeater K, McCouch S, McClung A (2013) Validation of yield-enhancing quantitative trait loci from a low-yielding wild ancestor of rice. Mol Breed 32:101-120. doi:10.1007/s11032-013-9855-7

Inukai T, Zeigler RS, Sarkarung S, Bronson M, Dung LV, Kinoshita T, Nelson RJ (1996) Development of pre-isogenic lines for rice blast-resistance by marker-aided selection from a recombinant inbred population. Theoret Appl Genetics 93:560-567. doi:10.1007/BF00417948

Kanbe T, Sasaki H, Aoki N, Yamagishi T, Ebitani T, Yano M, Ohsugi R (2008) Identification of QTLs for improvement of plant type in rice (Oryza sativa L.) using Koshihikari/ Kasalath chromosome segment substitution lines and backcross progeny $F_{2}$ population (genetic resources evaluation). Plant Prod Sci 11:447-456

Kawahara Y, de la Bastide M, Hamilton J, Kanamori H, McCombie WR, Ouyang S, Schwartz D, Tanaka T, Wu J, Zhou S (2013) Improvement of the Oryza sativa Nipponbare reference genome using next generation sequence and optical map data. Rice 6:1-10

Kinoshita T (1991) Report of the committee on gene symbolization, nomenclature and linkage groups. Rice Genet Newsl 8:2-37

Kinoshita T (1993) Report of the committee on gene symbolization, nomenclature and linkage groups. Rice Genet Newsl 10:7-39

Koide Y, Onishi K, Nishimoto D, Baruah AR, Kanazawa A, Sano Y (2008) Sex-independent transmission ratio distortion system responsible for reproductive barriers between Asian and African rice species. New Phytol 179:888-900. doi:10.1111/j.1469-8137.2008.02490.x

Kosambi DD (1943) The estimation of map distances from recombination values. Ann Eugen 12:172-175. doi:10.1111/ j.1469-1809.1943.tb02321.x

Kubo T, Aida Y, Nakamura K, Tsunematsu H, Doi K, Yoshimura A (2002) Reciprocal chromosome segment substitution series derived from japonica and indica cross of rice (Oryza sativa L.). Breed Sci 52:319-325

Lentini Z, Reyes P, Martínez CP, Roca WM (1995) Androgenesis of highly recalcitrant rice genotypes with maltose and silver nitrate. Plant Sci 110:127-138. doi:10.1016/01689452(95)04180-3

Li H, Ye G, Wang J (2007) A modified algorithm for the improvement of composite interval mapping. Genetics 175:361-374. doi:10.1534/genetics.106.066811

Li S, Yan S, Wang A-h, Zou G, Huang X, Han B, Qian Q, Tao Y (2013) Identification of QTLs associated with tissue culture response through sequencing-based genotyping of RILs derived from 93-11 × Nipponbare in rice (Oryza sativa). Plant Cell Rep 32:103-116. doi:10.1007/s00299-0121345-6

Lin H, Ashikari M, Yamanouchi U, Sasaki T, Yano M (2002) Identification and characterization of a quantitative trait locus, $H d 9$, controlling heading date in rice. Breed Sci 52:35-41

Ling WH, Cheng QX, Ma J, Wang T (2001) Red and black rice decrease atherosclerotic plaque formation and increase antioxidant status in rabbits. J Nutr 131:1421-1426

Liu G, Zhang Z, Zhu H, Zhao F, Ding X, Zeng R, Li W, Zhang G (2008) Detection of QTLs with additive effects and additive-by-environment interaction effects on panicle number in rice (Oryza sativa L.) with single-segment substitution lines. Theor Appl Genet 116:923-931. doi:10.1007/ s00122-008-0724-4

Lorieux M (2005) CSSL finder: a free program for managing introgression lines. http://mapdisto.free.fr/CSSLFinder/

Lorieux M (2012) MapDisto: fast and efficient computation of genetic linkage maps. Mol Breed 30:1231-1235. doi:10. 1007/s11032-012-9706-y. http://mapdisto.free.fr/CSSL Finder/

Lorieux M, Ndjiondjop M-N, Ghesquière A (2000) A first interspecific Oryza sativa $\times$ Oryza glaberrima microsatellite-based genetic linkage map. Theor Appl Genet 100: 593-601. doi:10.1007/s001229900061

Lorieux M, Tohme J, McCouch SR, Brondani C, Gridley H, Martinez CP, Diago M (2004) Exploring natural genetic variation: developing genomic resources and introgression lines for four AA genome rice relatives. A proposal to the Generation Challenge Program Standard Grant, pp 1-43

Lu B-R, Silitonga T (1999) Wild rice Oryza meridionalis was first found in Indonesia (notes from field). Int Rice Res Notes 24:28-30

Maas LF, McClung A, McCouch S (2010) Dissection of a QTL reveals an adaptive, interacting gene complex associated with transgressive variation for flowering time in rice. Theor Appl Genet 120:895-908. doi:10.1007/s00122-0091219-7

Marri PR, Sarla N, Reddy LV, Siddiq EA (2005) Identification and mapping of yield and yield related QTLs from an Indian accession of Oryza rufipogon. BMC Genet 6:33

Matsubara K, Khin-Thidar Sano Y (2003) A gene block causing cross-incompatibility hidden in wild and cultivated rice. Genetics 165:343-352

McCouch SR, Kochert G, Yu ZH, Wang ZY, Khush GS, Coffman WR, Tanksley SD (1988) Molecular mapping of rice chromosomes. Theoret Appl Genetics 76:815-829. doi:10.1007/BF00273666

McCouch SR, Teytelman L, Xu Y, Lobos KB, Clare K, Walton M, Fu B, Maghirang R, Li Z, Xing Y, Zhang Q, Kono I, Yano M, Fjellstrom R, DeClerck G, Schneider D, Cartinhour S, Ware D, Stein L (2002) Development and mapping of 2240 new SSR markers for rice (Oryza sativa L.). DNA Res 9:199-207. doi:10.1093/dnares/9.6.199

McCouch SR, Sweeney M, Li J, Jiang H, Thomson M, Septiningsih E, Edwards J, Moncada P, Xiao J, Garris A, Tai T, Martinez C, Tohme J, Sugiono M, McClung A, Yuan LP, Ahn S-N (2007) Through the genetic bottleneck: O. rufipogon as a source of trait-enhancing alleles for $O$. sativa. Euphytica 154:317-339. doi:10.1007/s10681-006-9210-8

McCouch S, Baute GJ, Bradeen J, Bramel P, Bretting PK, Buckler E, Burke JM, Charest D, Cloutier S, Cole G, Dempewolf H, Dingkuhn M, Feuillet C, Gepts P, Grattapaglia D, Guarino L, Jackson S, Knapp S, Langridge P, Lawton-Rauh A, Lijua Q, Lusty C, Michael T, Myles S, Naito K, Nelson RL, Pontarollo R, Richards CM, Rieseberg L, Ross-Ibarra J, Rounsley S, Hamilton RS, Schurr U, Stein N, Tomooka N, van der Knaap E, van Tassel D, Toll J, Valls J, Varshney RK, Ward J, Waugh R, Wenzl P, Zamir D (2013) Agriculture: feeding the future. Nature 499:23-24. doi:10.1038/499023a

Moncada P, Martínez CP, Borrero J, Chatel M, Gauch H Jr, Guimaraes E, Tohme J, McCouch SR (2001) Quantitative 
trait loci for yield and yield components in an Oryza sativa $\times$ Oryza rufipogon $B C_{2} F_{2}$ population evaluated in an upland environment. Theor Appl Genet 102:41-52. doi:10. 1007/s001220051616

Ng NQ, Hawkes JG, Williams JT, Chang TT (1981) The recognition of a new species of rice (Oryza) from Australia. Bot J Linn Soc 82:327-330. doi:10.1111/j.1095-8339. 1981.tb00964.x

Ogawa S, Selvaraj MG, Fernando AJ, Lorieux M, Ishitani M, McCouch S, Arbelaez JD (2014) $N$ - and $P$-mediated seminal root elongation response in rice seedlings. Plant Soil 1-13. doi:10.1007/s11104-013-1955-y

Orjuela J, Garavito A, Bouniol M, Arbelaez J, Moreno L, Kimball J, Wilson G, Rami J-F, Tohme J, McCouch S, Lorieux M (2009) A universal core genetic map for rice. Theor Appl Genet. doi:10.1007/s00122-009-1176-1

Panaud O, Chen X, McCouch SR (1996) Development of microsatellite markers and characterization of simple sequence length polymorphism (SSLP) in rice (Oryza sativa L.). Mol Gen Genet 252:597-607. doi:10.1007/BF02172406

Park KC, Kim NH, Cho YS, Kang KH, Lee JK, Kim N-S (2003) Genetic variations of AA genome Oryza species measured by MITE-AFLP. Theor Appl Genet 107:203-209. doi:10. 1007/s00122-003-1252-X

Periyannan S, Moore J, Ayliffe M, Bansal U, Wang X, Huang L, Deal K, Luo M, Kong X, Bariana H, Mago R, McIntosh R, Dodds P, Dvorak J, Lagudah E (2013) The gene Sr33, an ortholog of barley Mla genes, encodes resistance to wheat stem rust race $U g 99$. Science. doi:10.1126/science. 12390 28

Ray DK, Mueller ND, West PC, Foley JA (2013) Yield trends are insufficient to double global crop production by 2050 . PLoS ONE 8:e66428. doi:10.1371/journal.pone.0066428

Ren F, Lu B-R, Li S, Huang J, Zhu Y (2003) A comparative study of genetic relationships among the $A A$-genome Oryza species using RAPD and SSR markers. Theor Appl Genet 108:113-120. doi:10.1007/s00122-003-1414-x

Rha ES, Thseng FS, Wu ST (1995) Distorted segregation of marker genes in wide crosses of rice. J Agric Assoc China 170:104-123

Romero LE, Lozano I, Garavito A, Carabali SJ, Triana M, Villareal N, Reyes L, Duque MC, Martinez CP, Calvert L, Lorieux M (2014) Major QTLs control resistance to rice hoja blanca virus and its vector Tagosodes orizicolus. G3 4:133-142. doi:10.1534/g3.113.009373

Saintenac C, Zhang W, Salcedo A, Rouse MN, Trick HN, Akhunov E, Dubcovsky J (2013) Identification of wheat gene $\operatorname{Sr} 35$ that confers resistance to $U g 99$ stem rust race group. Science 341:783-786. doi:10.1126/science.12390 22

Sano Y (1990) The genic nature of gamete eliminator in rice. Genetics 125:183-191

Sarkarung S (1991) A simplified crossing method for rice breeding: a manual. CIAT, Cali

Sasaki A, Ashikari M, Ueguchi-Tanaka M, Itoh H, Nishimura A, Swapan D, Ishiyama K, Saito T, Kobayashi M, Khush GS, Kitano H, Matsuoka M (2002) Green revolution: a mutant gibberellin-synthesis gene in rice. Nature 416:701-702. doi:10.1038/416701a

Septiningsih EM, Trijatmiko KR, Moeljopawiro S, McCouch SR (2003) Identification of quantitative trait loci for grain quality in an advanced backcross population derived from the Oryza sativa variety IR64 and the wild relative $O$. rufipogon. Theor Appl Genet 107:1433-1441. doi:10.1007/ s00122-003-1376-z

Sonah H, Bastien M, Iquira E, Tardivel A, Légaré G, Boyle B, Normandeau É, Laroche J, Larose S, Jean M, Belzile F (2013) An improved genotyping by sequencing (GBS) approach offering increased versatility and efficiency of SNP discovery and genotyping. PLoS ONE 8:e54603. doi:10.1371/journal.pone.0054603

Song W-Y, Wang G-L, Chen L-L, Kim H-S, Pi L-Y, Holsten T, Gardner J, Wang B, Zhai W-X, Zhu L-H, Fauquet C, Ronald P (1995) A receptor kinase-like protein encoded by the rice disease resistance gene, $X a 21$. Science 270:18041806. doi:10.1126/science.270.5243.1804

Spindel J, Wright M, Chen C, Cobb J, Gage J, Harrington S, Lorieux M, Ahmadi N, McCouch S (2013) Bridging the genotyping gap: using genotyping by sequencing (GBS) to add high-density SNP markers and new value to traditional bi-parental mapping and breeding populations. Theor Appl Genet. doi:10.1007/s00122-013-2166-x

Sweeney MT, Thomson MJ, Pfeil BE, McCouch S (2006) Caught red-handed: $R c$ encodes a basic helix-loop-helix protein conditioning red pericarp in rice. Plant Cell 18:283-294. doi:10.1105/tpc.105.038430

Sweeney MT, Thomson MJ, Cho YG, Park YJ, Williamson SH, Bustamante CD, McCouch SR (2007) Global dissemination of a single mutation conferring white pericarp in rice. PLoS Genet 3:e133. doi:10.1371/journal. pgen.0030133

Tadege M, Sheldon CC, Helliwell CA, Upadhyaya NM, Dennis ES, Peacock WJ (2003) Reciprocal control of flowering time by $O S S O C 1$ in transgenic Arabidopsis and by FLC in transgenic rice. Plant Biotechnol J 1:361-369. doi:10. 1046/j.1467-7652.2003.00034.x

Takahashi Y, Shomura A, Sasaki T, Yano M (2001) Hd6, a rice quantitative trait locus involved in photoperiod sensitivity, encodes the $\alpha$ subunit of protein kinase CK2. PNAS 98:7922-7927. doi:10.1073/pnas.111136798

Tanksley SD, McCouch SR (1997) Seed banks and molecular maps: unlocking genetic potential from the wild. Science 277:1063-1066

Tanksley SD, Nelson JC (1996) Advanced backcross QTL analysis: a method for the simultaneous discovery and transfer of valuable QTLs from unadapted germplasm into elite breeding lines. Theoret Appl Genet 92:191-203. doi:10.1007/BF00223376

Tester M, Langridge P (2010) Breeding technologies to increase crop production in a changing world. Science 327: 818-822. doi:10.1126/science. 1183700

Thomson MJ, Tai TH, McClung AM, Lai X-H, Hinga ME, Lobos KB, Xu Y, Martinez CP, McCouch SR (2003) Mapping quantitative trait loci for yield, yield components and morphological traits in an advanced backcross population between Oryza rufipogon and the Oryza sativa cultivar Jefferson. Theor Appl Genet 107:479-493. doi:10. 1007/s00122-003-1270-8

Thomson MJ, Edwards JD, Septiningsih EM, Harrington SE, McCouch SR (2006) Substitution mapping of dth1.1, a flowering-time quantitative trait locus (QTL) associated with transgressive variation in rice, reveals multiple sub- 
QTL. Genetics 172:2501-2514. doi:10.1534/genetics.105. 050500

Tian F, Li D, Fu Q, Zhu Z, Fu Y, Wang X, Sun C (2006) Construction of introgression lines carrying wild rice (Oryza rufipogon Griff.) segments in cultivated rice (Oryza sativa $L$.) background and characterization of introgressed segments associated with yield-related traits. Theor Appl Genet 112:570-580. doi:10.1007/s00122-005-0165-2

Wang ZY, Second G, Tanksley SD (1992) Polymorphism and phylogenetic relationships among species in the genus Oryza as determined by analysis of nuclear RFLPs. Theoret Appl Genet 83:565-581. doi:10.1007/BF00226900

Xiao J, Li J, Grandillo S, Ahn SN, Yuan L, Tanksley SD, McCouch SR (1998) Identification of trait-improving quantitative trait loci alleles from a wild rice relative, Oryza rufipogon. Genetics 150:899-909

Xu Y, Zhu L, Xiao J, Huang N, McCouch SR (1997) Chromosomal regions associated with segregation distortion of molecular markers in $F_{2}$, backcross, doubled haploid, and recombinant inbred populations in rice (Oryza sativa L.). Mol Gen Genet 253:535-545

Xu J, Zhao Q, Du P, Xu C, Wang B, Feng Q, Liu Q, Tang S, Gu M, Han B, Liang G (2010) Developing high throughput genotyped chromosome segment substitution lines based on population whole-genome re-sequencing in rice (Oryza sativa L.). BMC Genom 11:656. doi:10.1186/1471-216411-656
Yano M, Katayose Y, Ashikari M, Yamanouchi U, Monna L, Fuse T, Baba T, Yamamoto K, Umehara Y, Nagamura Y, Sasaki T (2000) Hd1, a major photoperiod sensitivity quantitative trait locus in rice, is closely related to the arabidopsis flowering time gene CONSTANS. Plant Cell 12:2473-2483. doi:10.1105/tpc.12.12.2473

Yoshimura A, Nagayama H, Sobrizal, Kurakazu T, Sanchez PL, Doi K, Yamagata Y, Yasui H (2010) Introgression lines of rice (Oryza sativa L.) carrying a donor genome from the wild species, $O$. glumaepatula Steud. and $O$. meridionalis Ng. Breed Sci 60:597-603. doi:10.1270/jsbbs.60.597

Zamir D (2001) Improving plant breeding with exotic genetic libraries. Nat Rev Genet 2:983-989. doi:10.1038/3510 3590

Zhu Q, Ge S (2005) Phylogenetic relationships among A-genome species of the genus Oryza revealed by intron sequences of four nuclear genes. New Phytol 167:249-265. doi:10.1111/j.1469-8137.2005.01406.X

Zhu T, Xu P-Z, Liu J-P, Peng S, Mo X-C, Gao L-Z (2014) Phylogenetic relationships and genome divergence among the $A A$-genome species of the genus Oryza as revealed by 53 nuclear genes and 16 intergenic regions. Mol Phylogenet Evol 70:348-361. doi:10.1016/j.ympev.2013.10.008 